\title{
Estimativa da magnitude de riscos ocupacionais presentes em uma instalação radiativa e seus principais impactos à saúde
}

\author{
Alice dos Santos Alves, Eduardo Gerulis, Janete C. G. G. Carneiro ${ }^{\mathrm{a}}$ \\ ${ }^{I}$ Gerência de Radioproteção, Instituto de Pesquisas Energéticas e Nucleares (IPEN/CNEN-SP), \\ 05508-000, São Paulo-SP, Brasil \\ alicesante@usp.br
}

\begin{abstract}
RESUMO
A rotina de trabalho dos servidores do Centro de Radiofarmácia (CR) do Instituto de Pesquisas Energéticas e Nucleares (IPEN/CNEN-SP) inclui singularidades não existentes em outras categorias profissionais. Podem-se citar como exemplos relevantes para este estudo: a exposição aos riscos físicos, químicos, biológicos, de acidentes e ergonômicos. O principal objetivo deste trabalho é realizar uma avaliação quanti-qualitativa do risco ocupacional existente no ambiente de trabalho e seu impacto à saúde dos indivíduos ocupacionalmente expostos (IOE's). A metodologia proposta foi baseada na observação sistematizada e aplicação de um questionário aos gerentes de cada prática realizada no CR. O processo de avaliação envolveu três etapas: a) caracterização da exposição; b) identificação dos principais pontos de exposição e as possíveis vias de exposição; c) quantificação da exposição. Foram identificados dezessete agentes ocupacionais relacionados às tarefas dos diferentes grupos de IOE's, sendo que a radiação ionizante (risco físico) e as situações causadoras de estresse (risco ergonômico) apresentaram as maiores frequências. De acordo com a metodologia aplicada os riscos foram considerados na sua maioria aceitáveis. A quantificação da exposição foi basicamente referente ao agente de risco físico (radiação ionizante), pelo fato de se tratar de uma instalação radiativa. Com base nos registros analisados, não foi observado agravos à saúde dos trabalhadores decorrente das práticas realizadas.
\end{abstract}

Palavras-chave: Avaliação de risco; risco ocupacional; exposição ocupacional. 


\section{INTRODUÇÃO}

Qualquer pessoa está exposta a mais distinta condição que pode ocasionar eventos ou danos indesejados, seja no ambiente de trabalho, ou fora dele e que poderá afetar sua qualidade de vida. A esta possibilidade de ocorrerem danos indesejáveis denomina-se risco [1].

O risco, portanto, é a combinação da probabilidade de ocorrência e das consequências de um evento indesejado $[1,2]$.

Uma avaliação de risco caracteriza-se como um processo global de estimar a magnitude do risco e decidir se o risco é ou não aceitável. O risco deve ser determinado estimando-se a gravidade potencial do dano e a probabilidade de que o dano ocorra [2].

O processo de trabalho dos servidores do Centro de Radiofarmácia (CR) do Instituto de Pesquisas Energéticas e Nucleares (IPEN/CNEN-SP) inclui singularidades não existentes no processo de outras categorias profissionais. Podem-se citar como exemplos relevantes para este estudo: a exposição aos riscos físicos (radiações ionizantes), químicos (produtos químicos em geral - acetato de amônio; solventes - clorofórmio e substâncias inflamáveis - metanol), biológicos (objetos contaminados por bactérias), de acidentes (incêndios) e ergonômicos (trabalhos em turno).

O principal objetivo deste trabalho é realizar uma avaliação quanti-qualitativa do risco ocupacional existente no ambiente de trabalho e seu impacto à saúde dos indivíduos ocupacionalmente expostos do Centro de Radiofarmácia (CR).

A relevância deste estudo deu-se pela importância que a instalação radiativa tem em desenvolver e produzir radioisótopos e radiofármacos para a realização de diagnósticos e terapia em medicina nuclear. 


\section{MATERIAIS E MÉTODOS}

Atualmente a população do Centro de Radiofarmácia (CR), local de estudo, é composta por: 102 servidores públicos federais (50\%), 57 terceirizados $(27,94 \%)$ e 45 estudantes/estagiários $(22,06 \%)$. A amostra estudada foi constituída apenas pelos servidores públicos, representando $50 \%$ da população do CR. A coleta e análise dos dados ocorreram no período de abril de 2013 a junho de 2014.

O estudo envolveu um processo detalhado de avaliação, sendo composto por três etapas. A primeira etapa consistiu na caracterização básica da exposição relacionada às características físicas local de trabalho e de sua população. Para tanto, foi aplicado um questionário conduzido por entrevistas realizadas junto aos gerentes de cada grupo de tarefa. O questionário foi estruturado com questões abordando condições ambientais de trabalho, tarefa realizada, agentes de riscos e monitoramento ambiental e individual [3].

Dessa forma, foi possível compilar um inventário dos processos de trabalho, cargos, tarefas executadas pelos trabalhadores, tempo de trabalho, uso de equipamentos de proteção individual e coletiva e medidas de controle. Os aspectos sociodemográficos da amostra foram baseados em estudos recentes $[3,4]$.

$\mathrm{Na}$ segunda etapa foram identificados os principais pontos de exposição, obtidos por meio de monitoramentos e as possíveis vias de exposição.

A última etapa resumiu-se na quantificação da exposição, envolvendo uma avaliação do potencial de risco de um agente específico, presente no local de trabalho e sua probabilidade de ocasionar efeitos adversos à saúde da população exposta. A quantificação da exposição foi uma relação qualitativa entre exposição ocupacional e a presença de um efeito adverso à saúde. 
Para avaliação e quantificação dos prováveis riscos encontrados, utilizou-se o modelo de definição e julgamento dos perfis de exposição, proposto pela American Industrial Hygiene Association (AIHA), que diferencia as exposições ocupacionais em aceitáveis, incertas e inaceitáveis [5].

\section{RESULTADOS E DISCUSSÕES}

\subsection{Caracterização da Exposição}

O primeiro passo na avaliação da exposição potencial de um local de trabalho envolve a avaliação qualitativa desse local de trabalho [6]. A partir de uma avaliação subjetiva das informações inventariadas sobre o local de trabalho, força de trabalho e agentes, os trabalhadores foram agrupados em um "grupo de exposição homogênea" (GHE) que, em termos gerais, refere-se ao agrupamento dos trabalhadores expostos a uma mesma gama de agentes. As Figuras 1, 2, 3 e 4 apresentam as análises realizadas com base no inventário compilado da instalação em estudo.

A Figura 1 apresenta a distribuição dos trabalhadores de acordo com a tarefa e exposição homogênea (GHE).

Figura 1: Distribuição dos trabalhadores de acordo com a tarefa executada e exposição homogênea
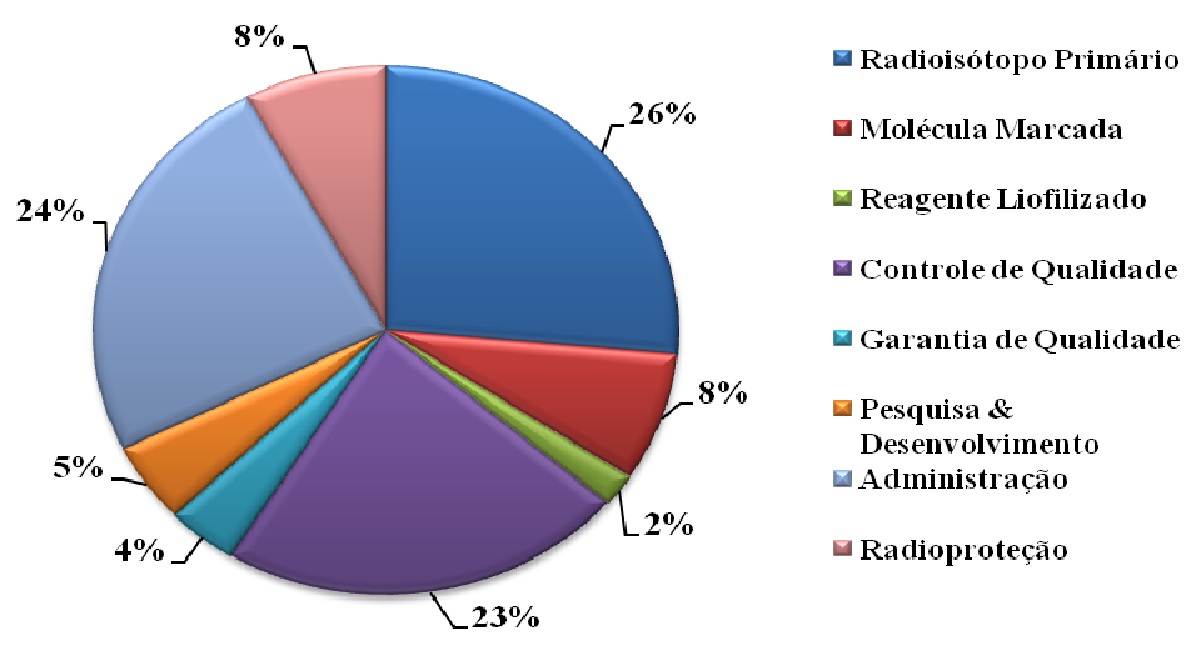
A Figura 2 mostra os principais riscos ocupacionais encontrados no ambiente laboral da instalação em estudo, CR.

Figura 2: Distribuição dos riscos ocupacionais presentes no ambiente de trabalho do CR

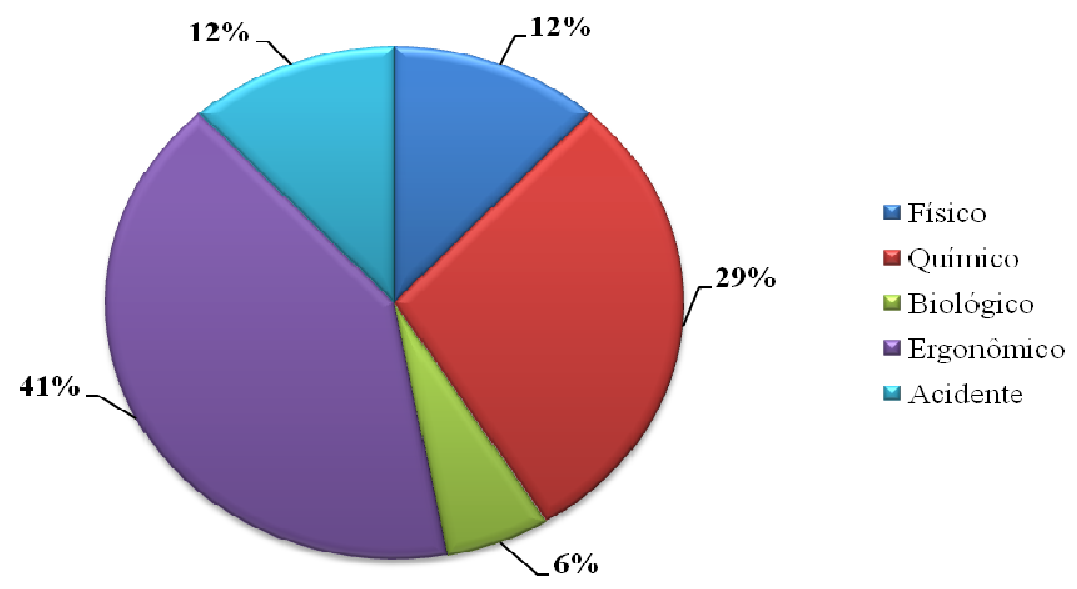

Na Figura 3 é apresentada a probabilidade do risco ocupacional de acordo com a tarefa realizada entre os grupos de exposição homogênea.

Figura 3: Identificação dos riscos ocupacionais entre os GHEs

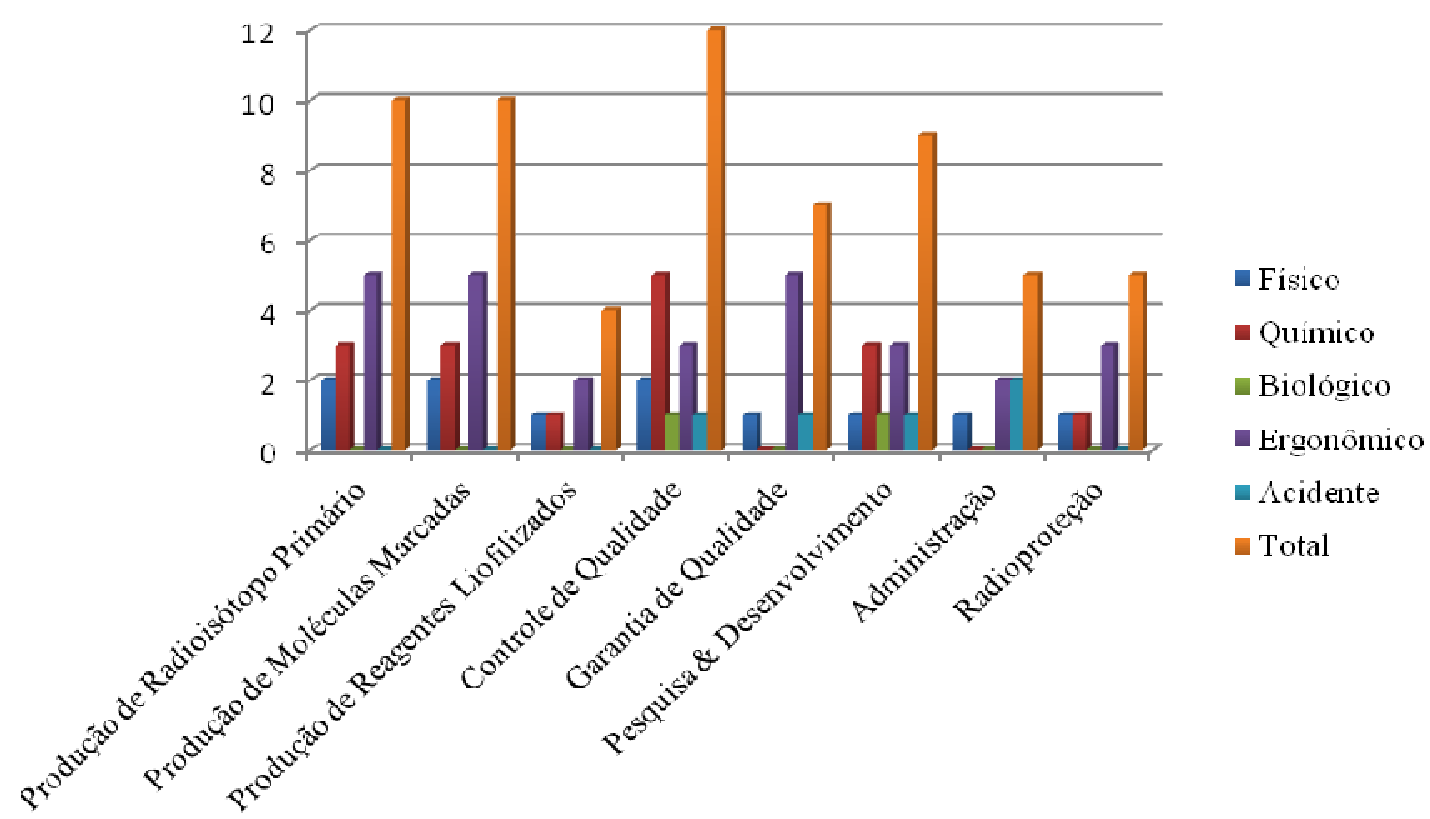


A Figura 4 apresenta a frequência dos agentes de riscos ocupacionais no ambiente de trabalho.

Figura 4: Frequência dos agentes de risco ocupacionais

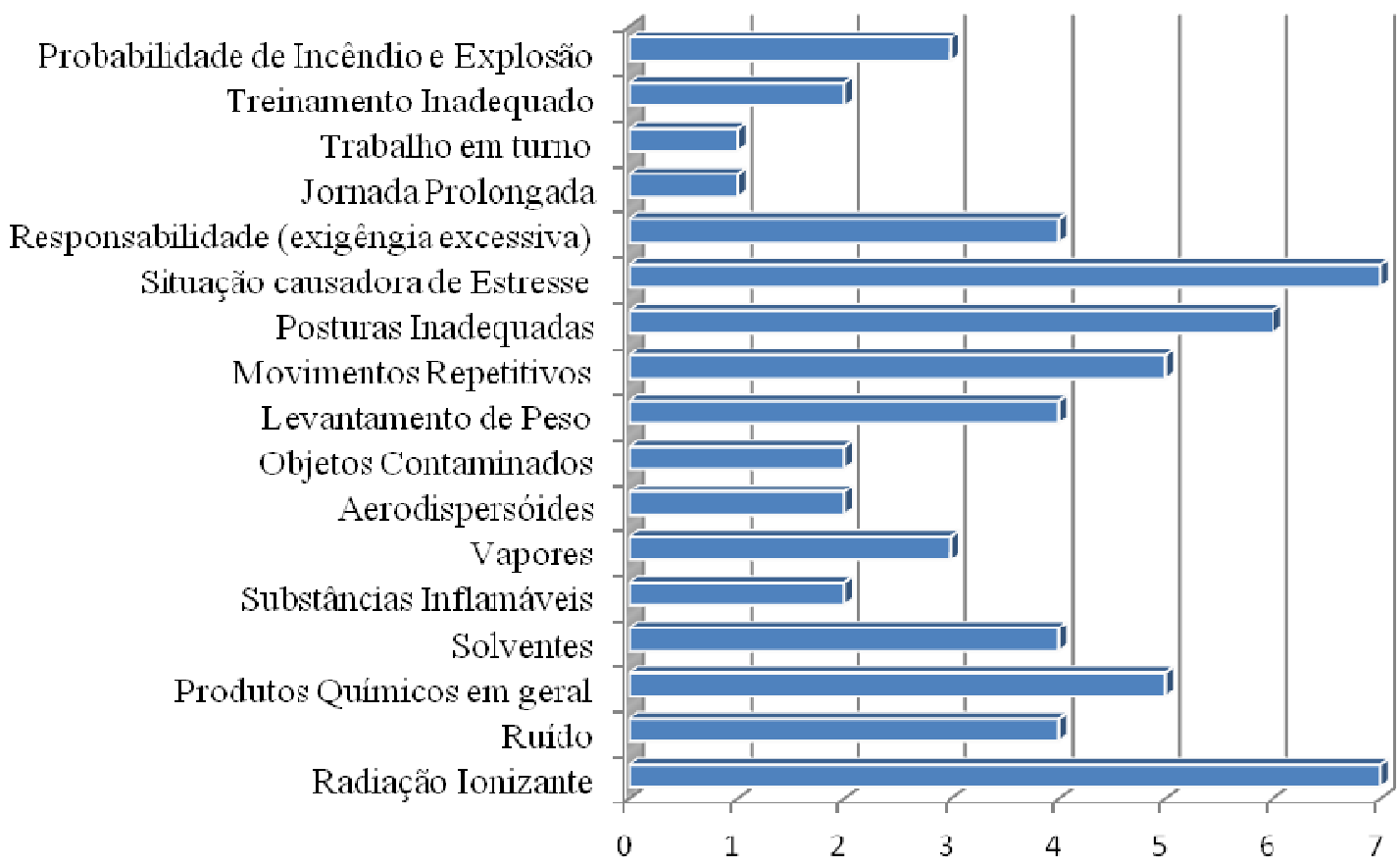

\subsection{Pontos e Vias de Exposição}

A instalação do CR abrange dois edifícios que manipulam radiofármacos. Ambos contam com proteções físicas e controle rigoroso de acesso. No edifício 1, executam-se o processamento dos radiofármacos (marcação), radioisótopos primários e a realização de pesquisas. No edifício 2 realizam-se os controles de qualidade do produto final e algumas pesquisas [7].

No interior dos edifícios 1 e 2, existem locais com possibilidade de exposição externa da radiação aos trabalhadores, bem como possibilidade de incorporação causada pelos materiais manuseados [7]. Também há a possibilidade de inalação, ingestão e contato com a pele/olhos de substâncias químicas manipuladas durante a marcação dos radiofármacos, testes para controle de qualidade e durante os experimentos de pesquisa. 
Estes locais são controlados com detectores de radiação ionizante e os indivíduos ocupacionalmente expostos, IOE's, utilizam equipamentos de proteção individual (EPI's) e coletiva (EPC's). A Tabela 1 apresenta os principais pontos de exposição, sua caracterização, as possíveis vias de exposição e os EPI's / EPC's de uso obrigatório.

Tabela 1: Identificação dos principais pontos de exposição e vias de exposição.

\begin{tabular}{|c|c|c|c|c|}
\hline Local & Caracterização & GHEs & $\begin{array}{c}\text { Via de } \\
\text { Exposição }\end{array}$ & $\begin{array}{l}\text { EPI's e } \\
\text { EPC's }\end{array}$ \\
\hline 1 & $\begin{array}{l}\text { Existente nos dois edifícios } \\
\text { e envolve as tarefas com } \\
\text { radiofármacos e radioisóto- } \\
\text { pos primários na forma lí- } \\
\text { quida em volumes pequenos } \\
\text { e com atividades pequenas. }\end{array}$ & $\begin{array}{c}\text { Controle de } \\
\text { Qualidade e } \\
\text { Pesquisa \& } \\
\text { Desenvolvimento }\end{array}$ & $\begin{array}{c}\text { Exposição } \\
\text { externa e } \\
\text { incorporação }\end{array}$ & $\begin{array}{l}\text { Dosímetro, } \\
\text { avental e } \\
\text { luvas }\end{array}$ \\
\hline 2 & $\begin{array}{l}\text { Existente apenas no edifício } \\
1 \text { e compreende as tarefas } \\
\text { com radiofármacos e radioi- } \\
\text { sótopos primários na forma } \\
\text { líquida com atividades } \\
\text { grandes, porém contidas } \\
\text { dentro das celas de proces- } \\
\text { samento ou embaladas para } \\
\text { transporte. }\end{array}$ & $\begin{array}{l}\text { Produção de } \\
\text { moléculas } \\
\text { marcadas }\end{array}$ & $\begin{array}{c}\text { Exposição } \\
\text { externa }\end{array}$ & $\begin{array}{l}\text { Dosímetro, } \\
\text { celas, } \\
\text { parede de } \\
\text { chumbo e } \\
\text { pinças } \\
\text { (garra) }\end{array}$ \\
\hline 3 & $\begin{array}{c}\text { Existente apenas no edifício } \\
1 \text { e envolve as tarefas com } \\
\text { radiofármacos e radioisóto- } \\
\text { pos primários na forma lí- } \\
\text { quida com atividades gran- } \\
\text { des dentro das celas, capelas } \\
\text { e glove boxes, conhecida por } \\
\text { ala-quente. }\end{array}$ & $\begin{array}{l}\text { Produção de } \\
\text { radioisótopos } \\
\text { primários }\end{array}$ & $\begin{array}{c}\text { Exposição } \\
\text { externa e } \\
\text { incorporação }\end{array}$ & $\begin{array}{l}\text { Dosímetro, } \\
\text { touca, bota } \\
\text { luvas, } \\
\text { máscaras } \\
\text { com filtros } \\
\text { e óculos } \\
\text { de prote- } \\
\text { ção }\end{array}$ \\
\hline
\end{tabular}

\subsubsection{Medidas de controle e monitoramento}

Em relação às medidas de controle individual, a equipe de Radioproteção realiza o monitoramento radiológico, por meio de dosímetro, detectores de pés e mãos e corpo inteiro. Também são monitoradas as descargas atmosféricas e executada a dosimetria de área. 
Outros monitoramentos são realizados pelo Serviço Especializado em Segurança do Trabalho (SEST), como por exemplo: medições pontuais de ruído, operações de riscos de explosão, medição de pressão de água dos hidrantes e medição do nível de iluminação. Após essas medições é emitido um laudo de conclusão e são tomadas as medidas cabíveis. Esses monitoramentos são solicitados quando em algum levantamento das condições de trabalho é verificado algum tipo de agente de risco que possa ser prejudicial ao trabalhador ou por solicitação de alguma área do CR.

\subsection{Quantificação da Exposição}

A avaliação dos processos de exposição aos agentes de risco ocupacional apresenta um desafio único para a quantificação das exposições, pois geralmente, durante a execução das tarefas, utilizam-se vários materiais e diferentes produtos químicos / radioativos [5].

Neste estudo, a quantificação da exposição foi basicamente referente ao agente de risco físico (radiação ionizante), pelo fato de se tratar de uma instalação radiativa. Os outros agentes foram baseados nos dados obtidos do inventário (análise sistemática de informações subjetivas), fornecidos pelos gerentes respondentes do questionário aplicado.

A análise dos dados obtidos envolveram as informações relacionadas aos processos, tarefas executadas, agentes de risco, limites de exposição ocupacional, avaliação da exposição, avaliação dos efeitos na saúde, avaliação dos riscos na saúde e avaliação das incertezas [5]. Na sequência, com os resultados obtidos no inventário determinou-se a aceitabilidade das exposições. A Tabela 2 apresenta a aceitabilidade das exposições aos agentes de risco envolvidos durante a execução das tarefas. 
Tabela 2: Determinação das exposições aos agentes de risco.

\begin{tabular}{|c|c|c|c|}
\hline Risco & Agente & Limite anual & $\begin{array}{l}\text { Critérios de } \\
\text { Aceitação * }\end{array}$ \\
\hline \multirow{2}{*}{ Físico } & Radiação Ionizante & $20 \mathrm{mSv} / \mathrm{a}[8]$ & Aceitável \\
\hline & Ruído & $85 \mathrm{~dB}[9]$ & Aceitável \\
\hline \multirow{5}{*}{ Químico } & Produtos químicos em geral & - & Incerto \\
\hline & Solventes & - & Incerto \\
\hline & Substâncias inflamáveis & - & Incerto \\
\hline & Vapores & - & Incerto \\
\hline & Aerodispersóides & - & Incerto \\
\hline Biológico & Objetos contaminados & - & Aceitável \\
\hline \multirow{7}{*}{ Ergonômico } & Levantamento de peso & - & Aceitável \\
\hline & Movimentos repetitivos & - & Aceitável \\
\hline & Postura inadequada & - & Aceitável \\
\hline & Situações causadoras de estresse & - & Aceitável \\
\hline & Responsabilidades & - & Aceitável \\
\hline & Jornada prolongada & - & Aceitável \\
\hline & Trabalho em turno & - & Aceitável \\
\hline \multirow{2}{*}{ Acidente } & Treinamento inadequado & - & Aceitável \\
\hline & Probabilidade de incêndio e explosões & - & Aceitável \\
\hline
\end{tabular}

Alguns produtos químicos não têm limites de exposição ocupacional e as informações utilizadas para definir os limites existentes são muitas vezes incompletas. A cada dia, novas informações toxicológicas e epidemiológicas são coletadas [5].

\subsubsection{Prováveis agravos à saúde}

A exposição combinada a agentes ocupacionais diferentes em uma instalação, frequentemente poderá produzir diferentes efeitos adversos à saúde. Por exemplo, alguns agentes podem ter efeitos sistêmicos reversíveis, alguns podem ser irritantes e outros podem ser carcinogênicos [6, 10]. A Tabela 3 apresenta os riscos ocupacionais e os prováveis agravos a que os trabalhadores possam estar expostos. 
Tabela 3: Riscos ocupacionais e seus prováveis agravos.

\begin{tabular}{cc}
\hline Riscos Ocupacionais & Consequências \\
\hline \multirow{3}{*}{ Físico } & $\begin{array}{c}\text { Eritema e queimaduras, perda de cabelo, catarata, distúrbios } \\
\text { sanguíneos, leucemia, vômitos/náusea, esterilidade, câncer, } \\
\text { aberração cromossômica e mutação genética. }\end{array}$ \\
& $\begin{array}{c}\text { Perda auditiva, aceleração da pulsação, aumento da pressão } \\
\text { sanguínea, secreções anormais de hormônios, tensões muscula- } \\
\text { res, nervosismo, fadiga mental, alterações no nível de atenção e } \\
\text { desempenho no trabalho [10, 11, 12]. }\end{array}$ \\
\hline & $\begin{array}{c}\text { Irritação das mucosas, olhos e pele, vermelhidão, coceira, der- } \\
\text { matite, dor de cabeça, vertigem/tonturas, sonolência, tosse, } \\
\text { pneumonite, perturbação visual, neuropatia periférica, doença } \\
\text { Químico } \\
\text { renal, distúrbios cardíacos, náuseas e vômitos, dor abdominal, } \\
\text { perda temporária de cabelo, palidez facial, lesão e aumento do } \\
\text { fígado [13]. }\end{array}$ \\
\hline Biológico & $\begin{array}{c}\text { Contaminações zoonóticas (zoonose), infecções (causadas pelo } \\
\text { contato direto com excretas, saliva, sangue ou tecidos coletados } \\
\text { em necropsias ou autópsias de espécies contaminadas) resposta } \\
\text { alérgica (corrimento nasal e ocular, lacrimejamento, espirros, } \\
\text { prurido, exantemas, tosse, dificuldade respiratória e asma) [14]. }\end{array}$ \\
\hline $\begin{array}{c}\text { Distúrbios osteomusculares, redução da produtividade no traba- } \\
\text { lho, acidentes, problemas cardiovasculares e mentais, doenças }\end{array}$ \\
musculoesqueléticas, fadiga, dores na coluna e cabeça, indiges- \\
tão, mialgia, fibromialgia, e distúrbios digestivos (síndrome do \\
intestino irritável) [15, 16].
\end{tabular}

\section{CONCLUSÕES}

A equipe de radioproteção do CR e a segurança física do IPEN atuam em concordância como os procedimentos operacionais estabelecidos e com as normas nacionais vigentes. Medidas de controle tais como, controle de engenharia, o uso de equipamentos de proteção individual, monitoração tanto de área como individual são realizados e quando necessário introduzem novos mecanismos para a mitigação do risco ocupacional visando o bem estar do trabalhador.

A radiação ionizante e as situações causadoras de estresse expressaram as maiores frequências, devido às propriedades físicas da matéria-prima utilizada e consequentemente a pressão psicológica para expedição dos radiofármacos de meia-vida curta com rapidez. 
Mensurar o estado de saúde e bem estar de uma determinada população exposta é, portanto, uma tarefa complexa, porém necessária para que sejam feitos diagnósticos e realizadas intervenções, na busca de um ambiente de trabalho saudável.

\section{REFERÊNCIAS}

1. ANJOS, A. M.; et al. Introdução à higiene ocupacional, São Paulo: FUNDACENTRO, 2004.

2. BS 8800:2004 - BRITISH STANDARDS. Occupational health and safety management systems - Guide. Standards Policy and Strategy Committee, Reino Unido, 2004. 70p.

3. ALVES A.; GERULIS E.; SANCHES M. P.; CARNEIRO J. C. G. G. Occupational exposure assessment in a radioactive facility: a preliminary evaluation, In: INTERNATIONAL NUCLEAR ATLANTIC CONFERENCE, 2013, Recife. Annals...Recife: XI Meeting on Nuclear Applications, 11th, 2013.

4. FERNANDES, I. M; SILVA, A. J; POTIENS, M. P. A; CARNEIRO, J. C. G. Avaliação da qualidade de vida de Trabalhadores com risco potencial às radiações ionizantes. Rev. Bras. Pesq. Des, v. 12, n 3, p. 164-169, 2010.

5. IGNACIO, J. S.; BULLOCK, W. H. A Strategy for assessing and managing occupational exposures, Third Edition, EUA: American Industrial Hygiene Association, 2006.

6. MENDES, R. Patologia do Trabalho, $2^{\circ}$ edição. São Paulo: Atheneu, 2007.

7. GERULIS, E. Controle da dose de radiação ionizante para trabalhadores em uma instalação radiativa com fontes não seladas. Instituto de Pesquisas Energéticas e Nucleares, São Paulo, 2006. 100p. 
8. CNEN - Comissão Nacional de Energia Nuclear. Diretrizes Básicas de Proteção Radiológica. Norma CNEN NN 3.01, 2011. 22p

9. MTE - Ministério do Trabalho e Emprego. Norma Regulamentadora $\mathbf{N}^{\mathbf{o}} \mathbf{1 5}$ - Atividades e Operações Insalubres. Portaria SIT n. ${ }^{\circ}$ 291, 2011. 82p.

10. UNSCEAR - United Nations Scientific Commite on the Effects of Atomic Radiation UNSCEAR 2000 Report. Sources and Effects of Ionizing Radiation. Vol II: Effects, Annex H: Combined effects of radiation an other agents, New York, 2001. 120p.

11. MCDONALD, C. Epidemiology of work related diseases, Second edition. London: BMJ Books, 2000.

12. SAMPAIO, C. A. P; NÄÄS, I. A; NADER, A. Gases e ruídos em edificações para suínos aplicação das normas NR-15, CIGR e ACGIH. Eng. Agríc., v. 25, p. 10-18, 2005.

13. NIOSH - National Institute for Occupational Safety and Health. NIOSH Pocket Guide to Chemical Hazards. Department of Health and Human Services - Centers for Disease Control and Prevention, Cincinnati: NIOSH Publications, 2007. 424p.

14. POLITI, F. A. S.; MAJEROWICZ, J.; CARDOSO, T. A. O.; PIETRO, R. C. L. R.; SALGADO, H. R. N. Caracterização de biotérios, legislação e padrões de biossegurança. Rev. Ciênc. Farm. Básica Apl., v. 29, p. 17-28, 2008.

15. ÁlvareZ, G. M. A; CARrillo, S. A. V.; RENDÓN, C. M. T. Principales patologías osteomusculares relacionadas con el riesgo ergonómico derivado de las actividades laborales administrativas. Revista CES Salud Pública, v. 2, p. 196-203, 2011. 
16. CHOI, S. M.; PARK, Y. S.; YOO, J. H.; KIM, G. Y. Occupational stress and physical symptoms among family medicine residents. Korean J Fam Med, v. 34, p. 49-57, 2013. 